\title{
Acceptance of SARS-CoV-2 vaccination among cancer patients in Portugal: attitudes and associated factors
}

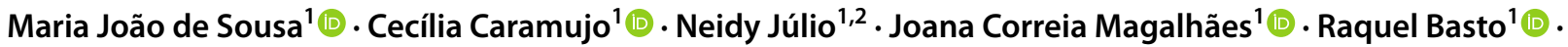

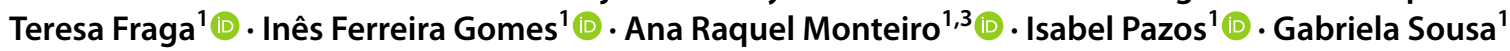

Received: 17 October 2021 / Accepted: 28 January 2022 / Published online: 4 February 2022

(c) The Author(s), under exclusive licence to Springer-Verlag GmbH Germany, part of Springer Nature 2022

\begin{abstract}
Objective COVID-19 vaccines have shown efficacy and safety in healthy people. However, cancer patients under active immunosuppressive treatment were not included in the clinical trials conducted to test vaccines' efficacy and safety. This study aimed to evaluate the COVID-19 vaccine acceptance in cancer patients undergoing immunosuppressive therapy.

Methods A total of 200 adult cancer patients received a questionnaire between March 8 and April 2, 2021, before the beginning of cancer patients' vaccination in Portugal. The questionnaire adapted from previously conducted studies included 11 close-ended items, evaluating variables such as patient sociodemographic and clinical characteristics, and the acceptance and underlying reasons to be or not to be vaccinated. The primary outcome was the intended acceptance of the COVID-19 vaccine in cancer patients. Multiple logistic regression was performed to identify factors associated with intended acceptance. Results Among the 200 delivered questionnaires, only 169 were included in this study. From those, $142(84 \%)$ patients intended to be vaccinated against COVID-19. Only 27 participants (16\%) had not yet decided or were reluctant to COVID19 vaccination. High school degree (odds ratio (OR) 0.133, 95\% confidence interval (C.I.) $0.031-0.579, p=0.007]$, rural residence (OR $0.282,95 \%$ C.I. $0.081-0.984, p=0.047$ ), and reluctance in believing in the vaccine efficacy (OR $0.058,95 \%$ C.I. 0.016-0.204, $p<0.001]$ were identified predictors factor for COVID-19 vaccine hesitancy.

Conclusion Most patients intended to be vaccinated against COVID-19, and specific factors such as education level, rural residence and the belief in vaccine efficacy were related to vaccine acceptance.
\end{abstract}

Keywords Cancer · Vaccination · Acceptance $\cdot$ COVID-19

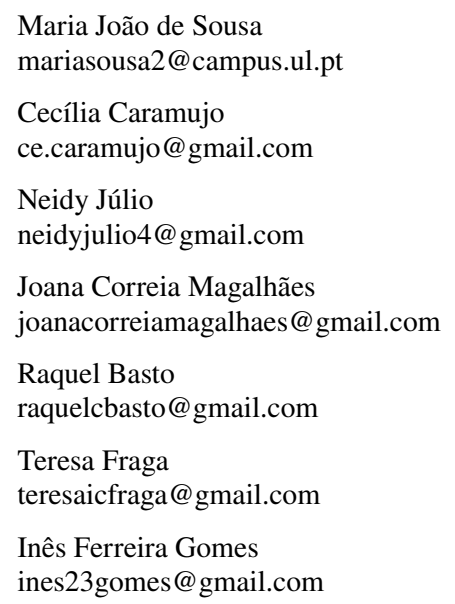

\author{
Ana Raquel Monteiro \\ anaraquelmonteiro13@gmail.com \\ Isabel Pazos \\ mariaisabelpazos@gmail.com
}

Gabriela Sousa

3036@ipocoimbra.min-saude.pt

1 Medical Oncology Department, Instituto Português de Oncologia de Coimbra Francisco Gentil E.P. E. (IPO Coimbra), Coimbra, Portugal

2 Internal Medicine Department, Hospital Militar Principal de Luanda, Luanda, Angola

3 Medical Oncology Department, Centro Hospitalar Vila Nova de Gaia/Espinho, Vila Nova de Gaia, Portugal 


\section{Introduction}

Severe acute respiratory syndrome coronavirus 2 (SARSCoV-2) was first detected in Wuhan, China, in late December 2019. COVID-19 was the name attributed by the World Health Organization (WHO) to the disease caused by SARS-CoV-2. The COVID-19 pandemic spread around the world at an alarming pace. As of 28 September 2021, over 231 million have been globally diagnosed with this disease and the cumulative number of deaths was more than 4.7 million [1].

Cancer patients have been identified as a particularly vulnerable subgroup of patients. Susceptibility to COVID19 highly depends on tumor type, type of treatment, and patients' characteristics. Nevertheless, an increased risk of severe COVID-19 was detected in cancer patients with advanced age, preexisting conditions, and hematological and lung malignancies [2-4].

The COVID-19 pandemic remains a threat to public health, with an impact on socioeconomic and cultural development worldwide. To effectively control this disease, a significant part of the population needs to acquire immunity, which is best achieved through vaccination. International efforts have led to the development and approval of several vaccines that have shown efficacy and safety in healthy people, less than 12 months after the outbreak of this pandemic [5-8]. However, none of the clinical trials evaluating the effectiveness and safety of the vaccines included cancer patients under active immunosuppressive treatment, creating doubts regarding the management of the vaccination process of cancer patients for whom vaccination may have a reduced effect and/or greater risk of adverse events.

Although there is no definitive data on the safety or effectiveness of the currently authorized vaccines in patients being treated for cancer, based on data extrapolation from other vaccines and the mechanism of action of the COVID-19 vaccines, it is conceivable that the efficacy and safety of vaccination against COVID-19 may be estimated to be similar to that of patients without cancer [9]. This provides a rationale for the current recommendations advising cancer patients to receive immunization against COVID-19 $[9,10]$.

COVID-19 vaccine acceptance rates vary among the general population aged 18 and above worldwide [11]. A European survey showed similar vaccine acceptance rates among seven countries varying from 62 in France to $80 \%$ in Denmark. Vaccine hesitancy was exhibited in $19 \%$ of the participants [12]. Among oncologic patients, a high hesitancy rate to receive a COVID-19 vaccine is perceived [13-15]. A study by Barrier et al. applied an anonymous questionnaire to oncology patients and showed that among the participants, $53.7 \%$ intended to be vaccinated as soon as the vaccine was available [13]. The remaining declared that they were not ready yet to be vaccinated but likely to change their mind (29.7\%), and only $16.6 \%$ of the participants would refuse vaccination.

Our study aimed to evaluate the COVID-19 vaccine acceptance in cancer patients undergoing immunosuppressive therapy in a Portuguese cancer center by applying a questionnaire adapted from the study by Barrier et al. and understand which factors are associated with COVID-19 vaccine hesitancy.

\section{Materials and methods}

\section{Study design and participants}

We conducted a single-center cross-sectional study by applying an anonymous survey to both in and outpatients aged $\geq 18$ years with a solid malignancy under treatment with chemotherapy, cyclin-dependent kinases (CDK) inhibitors, tyrosine kinase inhibitors (TKIs), monoclonal antibodies, or immunotherapy at the Portuguese Oncology Institute of Coimbra Francisco Gentil, an oncological hospital located in central Portugal. Patients previously vaccinated against COVID-19 were excluded. The questionnaire was distributed between March 8 and April 2, 2021. During this period in Portugal, the first vaccination phase was occurring in people aged 80 years or older and in people over 50 with at least one of the following comorbidities: cardiac insufficiency; coronary heart disease; renal failure (defined as glomerular filtration rate $<60 \mathrm{ml} / \mathrm{min}$ ), and chronic obstructive pulmonary disease or chronic respiratory disease under long-term ventilatory support and/or oxygen therapy.

\section{Procedures}

An 11-item questionnaire to assess the acceptance of the COVID-19 vaccine was adapted from a previous study [13] and can be consulted in the supplement. Participants were required to provide written informed consent before enrollment. For illiterate participants, the questionnaire was administered by trained research assistants.

The questionnaire was divided into three domains, with the first domain assessing sociodemographic characteristics, such as age, sex, marital status, education, and area of residence. The second domain assessed seasonal influenza vaccination during the past flu season, history of previous COVID-19 infection, suspicion or fear of being infected with COVID-19, belief in the effectiveness of the vaccine, and acceptance to be vaccinated. The third domain evaluated the reason behind the patient intention regarding vaccination. All questions were close ended, with tick boxes provided for responses. In the third domain, all reasons behind the 
patient's decision were asked to fill out. Questionnaires were subsequently subjected to quality control and manual verification procedures to exclude those which were incomplete and/or incorrectly filled.

\section{Statistical analysis}

Statistical analysis involved descriptive statistical measures (absolute and relative frequencies, means, and standard deviations) and inferential statistics. To identify the significant predictors of the intention to be vaccinated against COVID19 , a multiple logistic regression was used with this variable as dependent and the variables of age, sex, marital status, education, area of residence, treatment intention, seasonal influenza vaccination during the past flu season, history of previous COVID-19 infection, suspicion of being infected with COVID-19, and belief in the effectiveness of the vaccine as independent variables or predictors. Qualitative variables were transformed into variables dummy. A $p$ value of $<0.05$ was considered statistically significant. Data were analyzed using Statistical Package for the Social Sciences (SPSS), version 27.

\section{Ethics approval}

The study was extensively reviewed and subsequently approved by the Ethics Committee of the Portuguese Oncology Institute of Coimbra Francisco Gentil and conducted in accordance with the ethical standards laid down in the 1964 Declaration of Helsinki and its later amendments or comparable ethical standards. Informed consent was obtained from and signed by all subjects involved in the study.

\section{Results}

\section{Patient, tumor, and cancer treatment characteristics}

Among the 200 delivered questionnaires, 169 (84.5\%) analyzable forms were validated and included in this study. The remaining 31 questionnaires were excluded as they were incomplete and/or incorrectly filled. Patient, tumor, and treatment characteristics are presented in Table 1. The studied population had a median age of 61 years old (29-82), 109 (64.5\%) were female, and 106 (62.7\%) had Eastern Cooperative Oncology Group Performance Status (ECOG-PS) of grade 0. More than half $(105,62.1 \%)$ had a lower literacy degree (below secondary education), 97 (57.4\%) resided in the countryside, and $111(65.7 \%)$ were married. Regarding primary tumor location, 72 (42.6\%) were located in the breast, $28.4 \%$ in the digestive system,
Table 1 Sociodemographic and clinical characteristics of the participants. Total number of participants: 163

\begin{tabular}{|c|c|c|}
\hline & Number $(n)$ & Percentage $(\%)$ \\
\hline \multicolumn{3}{|l|}{ Gender } \\
\hline Male & 60 & 35.5 \\
\hline Female & 109 & 64.5 \\
\hline \multicolumn{3}{|l|}{ Education } \\
\hline Elementary & 80 & 47.3 \\
\hline Middle & 25 & 14.8 \\
\hline Secondary & 39 & 23.1 \\
\hline University or above & 25 & 14.8 \\
\hline \multicolumn{3}{|l|}{ Marriage status } \\
\hline Single & 17 & 10.1 \\
\hline Married & 111 & 65.7 \\
\hline Divorced & 23 & 13.6 \\
\hline Widowed & 18 & 10.7 \\
\hline \multicolumn{3}{|l|}{ Residence } \\
\hline Urban & 72 & 42.6 \\
\hline Rural & 97 & 57.4 \\
\hline \multicolumn{3}{|l|}{ ECOG-PS grade } \\
\hline 0 & 106 & 62.7 \\
\hline 1 & 54 & 32.0 \\
\hline 2 & 9 & 5.3 \\
\hline \multicolumn{3}{|l|}{ Tumor location } \\
\hline Breast & 72 & 42.6 \\
\hline Urological & 11 & 6.5 \\
\hline Digestive & 48 & 28.4 \\
\hline Lung & 13 & 7.7 \\
\hline Skin & 6 & 3.6 \\
\hline Gynecological & 3 & 1.8 \\
\hline Head and neck & 10 & 5.9 \\
\hline Sarcoma & 2 & 1.2 \\
\hline Central nervous system & 4 & 2.4 \\
\hline \multicolumn{3}{|l|}{ Treatment intention } \\
\hline Adjuvant & 38 & 22.5 \\
\hline Palliative & 87 & 51.5 \\
\hline Intensive & 6 & 3.6 \\
\hline Neoadjuvant & 38 & 22.5 \\
\hline
\end{tabular}

and 29\% were located in other organs. Approximately half of the patients $(87,51.5 \%)$ were undergoing palliative immunosuppressive therapy, whereas $22.5 \%$ received adjuvant treatment, $22.5 \%$ neoadjuvant treatment, and $3.6 \%$ intensive treatment.

The majority of the interviewed patients $(112,66.3 \%)$ had not taken the seasonal influenza vaccination in the previous season, 16 (9.5\%) patients had a history of previous COVID-19 infection, and 15 (8.9\%) were suspected of having been infected with unconfirmed COVID-19. 
Table 2 Multiple logistic regression on factors associated with the acceptance of COVID-19 vaccination

\begin{tabular}{|c|c|c|c|c|c|c|}
\hline & \multirow[t]{2}{*}{$B$} & \multirow[t]{2}{*}{ S.E. } & \multirow[t]{2}{*}{$p$ value } & \multirow[t]{2}{*}{ Odds ratio } & \multicolumn{2}{|c|}{ 95\% C.I. } \\
\hline & & & & & $L$ & $U$ \\
\hline Age & 0.020 & 0.033 & 0.532 & 1,021 & 0.958 & 1.088 \\
\hline \multicolumn{7}{|l|}{ Tumor location } \\
\hline Breast & -0.094 & 1.460 & 0.949 & 0.910 & 0.052 & 15.918 \\
\hline Digestive & $-1,048$ & 1.368 & 0.444 & 0.351 & 0.024 & 5.123 \\
\hline Lung & -0.495 & 1.402 & 0.724 & 0.610 & 0.039 & 9.527 \\
\hline Treatment intention (reference to adjuvant) & & & 0.792 & & & \\
\hline Palliative & -0.827 & 0.864 & 0.338 & 0.437 & 0.081 & 2.377 \\
\hline Intensive & -0.311 & 1.838 & 0.866 & 0.733 & 0.020 & 26.871 \\
\hline Neoadjuvant & -0.372 & 0.877 & 0.672 & 0.690 & 0.124 & 3.845 \\
\hline Education (reference to elementary) & & & 0.023 & & & \\
\hline Middle & 1.070 & 1.300 & 0.411 & 2.914 & 0.228 & 37.249 \\
\hline Secondary & -2.015 & 0.749 & $0.007 *$ & 0.133 & 0.031 & 0.579 \\
\hline University or above & -0.936 & 1.064 & 0.379 & 0.392 & 0.049 & 3.154 \\
\hline Marriage status (reference to single) & & & 0.166 & & & \\
\hline Married & 1.695 & 0.910 & 0.063 & 5.444 & 0.915 & 32.396 \\
\hline Divorced & 2.496 & 1.197 & $0.037 *$ & 12.139 & 1.163 & 126.747 \\
\hline Widowed & 2.490 & 1.381 & 0.071 & 12.060 & 0.805 & 180.593 \\
\hline Rural residence & -1.267 & 0.638 & $0.047^{*}$ & 0.282 & 0.081 & 0.984 \\
\hline Participants previously vaccinated for flu & 0.906 & 0.699 & 0.195 & 2.474 & 0.629 & 9.735 \\
\hline Participants that had already been infected with SARS-Cov-2 & 0.938 & 0.921 & 0.308 & 2.556 & 0.420 & 15.554 \\
\hline Participants that had already suspected to be infected with SARS-CoV-2 & 0.249 & 0.988 & 0.801 & 1.283 & 0.185 & 8.901 \\
\hline Participants that were unsure about vaccine efficacy & -2.852 & 0.645 & $0.000 * * *$ & 0.058 & 0.016 & 0.204 \\
\hline Constant & 1.983 & 2.867 & 0.489 & 7.265 & & \\
\hline
\end{tabular}

$* p \leq .05 ; * * p \leq .01 ; * * * p \leq .001 ; \mathrm{L}$ : lower limit; U: upper limit

\section{Acceptance and motivation reasons for COVID-19 vaccination}

One hundred and thirty-four patients (79.3\%) trusted the ability of the vaccine to prevent and control COVID-19, 142 (84\%) intended to be vaccinated, 24 (14.2\%) were unsure, and $3(1.8 \%)$ did not plan to be vaccinated. All the negative answers were given by patients receiving palliative treatment. The majority of patients that were unsure (14, 58.3\%) had a higher literacy degree than the high school degree.

Logistic regression analysis showed participants who were reluctant about vaccine efficacy in the prevention and control of COVID-19 infection (OR 0.058, 95\% C.I. $0.016-0.204, p<0.001]$ were more likely to live in rural areas (OR 0.282, 95\% C.I. $0.081-0.984, p=0.047$ ) and more likely to have high school degrees (OR 0.133 , 95\% C.I. $0.031-0.579, p=0.007$ ) (Table 2). Divorced people (OR $12.139,95 \%$ C.I. $1.163-126.74, p=0.037$ ) were more likely to accept COVID-19 vaccination. The other studied factors were not significant in multivariable analysis, namely age, tumor location, treatment intention, have been previously vaccinated for flu, or have been infected or already suspected to be infected with SARS-CoV-2.
Patients were asked to sign all the reasons why they wanted or did not to receive the vaccine. The most frequently reported reasons for wanting to be vaccinated were related to collective responsibility $(112,66.3 \%)$ and fear of having severe COVID-19 (109, 64.5\%). Among the three patients that did not plan to be vaccinated, the most frequently appointed reasons for not wanting to be vaccinated were associated with lack of information regarding the use of the vaccine in oncological patients $(2,66.7 \%)$ and preference for waiting for the end of treatments $(2,66.7 \%)$. On the other hand, the main reasons for uncertainty related to the vaccine among the 24 patients were related to the need for more information on effectiveness $(12,50.0 \%)$ and safety $(18,75.0 \%)$.

\section{Discussion}

In our study, $84 \%$ of cancer patients intended to be vaccinated against COVID-19, only $16 \%$ had not yet decided or were reluctant. Importantly, the likelihood of the subjects wanting to be vaccinated was lower in participants with the secondary grade when compared to those with the primary 
grade, lower in rural areas, when compared to urban residents, and lower in subjects who doubted that a vaccine for a COVID-19 is an effective way to prevent and control a COVID-19 disease. In contrast, divorced people were more likely to accept COVID-19.

In contrast with previous studies, a high acceptance rate was found in Portuguese cancer patients. In fact, we found that $84 \%$ of cancer patients enrolled in this study intended to be vaccinated in comparison with, for instance, $53.7 \%$ in France or $17.9 \%$ in Hong Kong [13, 15]. However, our study occurred later in time, which might have promoted a higher vaccine knowledge and demystification of specific concerns related to COVID-19 vaccination impact in cancer patients.

All patients who were refusers were in palliative care. In fact, these patients are less concerned about getting COVID and therefore they might prefer to wait for deeper knowledge in vaccine administration rather than take the risk. These participants referred "lack of information regarding the use of the vaccine in oncological patients" and "preference for waiting for the end of treatments" as the main reason for their decision.

Vaccine acceptance/hesitancy is affected by multiple factors from sociodemographic to political and cultural issues, with distinct consequences across different populations [16]. Our study pinpointed factors such as less education level and living in a rural area as predictor factors for hesitancy in COVID-19 vaccination. Importantly, they have been already consistently reported both in cancer patients [14] as well as among the general population [16]. Although previous studies showed that participants who previously received an influenza vaccine were more likely to accept a COVID-19 vaccine $[16,17]$; in our work, this variable was not significantly associated with vaccination intention.

To the best of our knowledge, this is the first study reporting the acceptance of the COVID-19 vaccine in cancer patients from Portugal and the study with the highest vaccine acceptance rate reported in cancer patients. We attribute this high acceptance rate to the fact that the population highly trusted the service providers and recognized the good quality of Portuguese health service. In fact, approximately $80 \%$ of patients believed in the ability of the vaccine to prevent and control the COVID-19 disease. To achieve this, clear and credible communication strategies were carried out by the Portuguese government and health services, with the help of social media, raising awareness of the benefits of vaccination, which addressed patient misinformation and concerns.

Despite being the first study characterizing COVID-19 vaccine acceptance among Portuguese cancer patients, the study has some limitations, namely the cross-sectional nature of the study, which does not allow the assessment of the causality among the different outcomes evaluated such as predictor factors and the likelihood of vaccine acceptance. Moreover, the inclusion of only one institution might have limited the generalizability of the results once it is not representative of the Portuguese population. The distribution of a questionnaire that was not previously validated may fail to grasp all reasons for the acceptance/refusal of vaccination and the fact that the vaccination rate among the included patients was not assessed did not allow to confirm the real COVID-19 vaccine acceptance. Finally, the limited sample size in reluctant and refuser groups hindered the precise definition of predictor factors for vaccine acceptance. Hesitancy measurement could have been held differently to increase sensitivity (i.e., the use of a Likert scaling of hesitancy with scale point responses, making this variable continuous instead of a dichotomic variable). Although clear advice on how to improve vaccination rates in these groups is not possible to provide, the elevated acceptance pattern among Portuguese cancer patients is undeniable.

\section{Conclusion}

Despite the lack of information on the effectiveness, duration of the immune response, safety, and the best timing for the administration of the vaccine in oncological patients under immunosuppressive treatment, this study was able to demonstrate that the majority of patients intend to be vaccinated against COVID-19. These results were related to residence type, literacy, and belief in the effectiveness of the vaccine. The higher acceptance rate in our study, when compared with other studies, must also be noted.

Author contribution All authors contributed to the study conception and design. Material preparation, data collection, and analysis were performed by Maria João de Sousa, Cecília Caramujo, Neidy Júlio, Joana Correia Magalhães, Raquel Basto, Teresa Fraga, and Inês Ferreira Gomes. Supervision was performed by Ana Raquel Monteiro, Isabel Pazos, and Gabriela Sousa. The first draft of the manuscript was written by Maria João de Sousa, and all authors commented on previous versions of the manuscript. All authors read and approved the final manuscript.

Data availability For any data or certificate requests, please contact the corresponding author.

Code availability Not applicable.

\section{Declarations}

Ethics approval The study was extensively reviewed and subsequently approved by the Ethics Committee of the Portuguese Oncology Institute of Coimbra Francisco Gentil and conducted in accordance with the ethical standards laid down in the 1964 Declaration of Helsinki and its later amendments or comparable ethical standards.

Consent to participate Informed consent was obtained from and signed by all subjects involved in the study. 
Consent for publication Not applicable.

Conflict of interest The authors declare no competing interests.

\section{References}

1. World Health Organization (2021) Weekly epidemiological update on COVID-19 - 28 September 2021. In: Emerg. Situational Updat. https://www.who.int/publications/m/item/weekly-epidemiolo gical-update-on-covid-19\%2D\%2D-28-september-2021. Accessed 1 Oct 2021

2. Rüthrich MM, Giessen-Jung C, Borgmann S, Classen AY, Dolff S, Grüner B, Hanses F, Isberner N, Köhler P, Lanznaster J, Merle U, Nadalin S, Piepel C, Schneider J, Schons M, Strauss R, Tometten L, Vehreschild JJ, von Lilienfeld-Toal M et al (2021) COVID-19 in cancer patients: clinical characteristics and outcome - an analysis of the LEOSS registry. Ann Hematol 100:383-393. https://doi. org/10.1007/S00277-020-04328-4

3. Lee LYW, Cazier J-B, Starkey T, Briggs SEW, Arnold R, Bisht V, Booth S, Campton NA, Cheng VWT, Collins G, Curley HM, Earwaker P, Fittall MW, Gennatas S, Goel A, Hartley S, Hughes DJ, Kerr D, Lee AJX et al (2020) COVID-19 prevalence and mortality in patients with cancer and the effect of primary tumour subtype and patient demographics: a prospective cohort study. Lancet Oncol 21:1309-1316. https://doi.org/10.1016/S1470-2045(20) 30442-3

4. Luo J, Rizvi H, Preeshagul IR, Egger JV, Hoyos D, Bandlamudi C, McCarthy CG, Falcon CJ, Schoenfeld AJ, Arbour KC, Chaft JE, Daly RM, Drilon A, Eng J, Iqbal A, Lai WV, Li BT, Lito P, Namakydoust A et al (2020) COVID-19 in patients with lung cancer. Ann Oncol 31:1386. https://doi.org/10.1016/J.ANNONC. 2020.06.007

5. Baden LR, Sahly HM El, Essink B, Kotloff K, Frey S, Novak R, Diemert D, Spector SA, Rouphael N, Creech CB, McGettigan J, Khetan S, Segall N, Solis J, Brosz A, Fierro C, Schwartz H, Neuzil K, Corey L, Gilbert P, Janes H, Follmann D, Marovich M, Mascola J, Polakowski L, Ledgerwood J, Graham BS, Bennett H, Pajon R, Knightly C, Leav B, Deng W, Zhou H, Han S, Ivarsson M, Miller J, Zaks T (2020) Efficacy and safety of the mRNA1273 SARS-CoV-2 vaccine. 384:403-416 . https://doi.org/10. 1056/NEJMOA2035389

6. Polack FP, Thomas SJ, Kitchin N, Absalon J, Gurtman A, Lockhart S, Perez JL, Marc GP, Moreira ED, Zerbini C, Bailey R, Swanson KA, Roychoudhury S, Koury K, Li P, Kalina W V., Cooper D, Robert W. Frenck J, Hammitt LL, Türeci Ö, Nell H, Schaefer A, Ünal S, Tresnan DB, Mather S, Dormitzer PR, Şahin U, Jansen KU, Gruber WC (2020) Safety and efficacy of the BNT162b2 mRNA COVID-19 vaccine. 383:2603-2615. https:// doi.org/10.1056/NEJMOA2034577

7. Voysey M, Clemens SAC, Madhi SA, Weckx LY, Folegatti PM, Aley PK, Angus B, Baillie VL, Barnabas SL, Bhorat QE, Bibi S, Briner C, Cicconi P, Collins AM, Colin-Jones R, Cutland CL, Darton TC, Dheda K, Duncan CJA et al (2021) Safety and efficacy of the ChAdOx1 nCoV-19 vaccine (AZD1222) against SARSCoV-2: an interim analysis of four randomised controlled trials in Brazil, South Africa, and the UK. Lancet 397:99-111. https:// doi.org/10.1016/S0140-6736(20)32661-1
8. Logunov DY, Dolzhikova IV, Shcheblyakov DV, Tukhvatulin AI, Zubkova OV, Dzharullaeva AS, Kovyrshina AV, Lubenets NL, Grousova DM, Erokhova AS, Botikov AG, Izhaeva FM, Popova O, Ozharovskaya TA, Esmagambetov IB, Favorskaya IA, Zrelkin DI, Voronina DV, Shcherbinin DN et al (2021) Safety and efficacy of an rAd26 and rAd5 vector-based heterologous primeboost COVID-19 vaccine: an interim analysis of a randomised controlled phase 3 trial in Russia. Lancet 397:671-681. https:// doi.org/10.1016/S0140-6736(21)00234-8

9. Garassino MC, Giesen N, Grivas P, Jordan K, Lucibello F, Mir O, Pentheroudakis G, LastNameLastNameLastNamScotté F (2021) COVID-19 vaccination in cancer patients: ESMO statements. https://www.esmo.org/covid-19-and-cancer/covid-19-vaccination. Accessed 1 Oct 2021

10. Garassino MC, Vyas M, de Vries EGE, Kanesvaran R, Giuliani R, Peters S (2021) The ESMO call to action on COVID-19 vaccinations and patients with cancer: vaccinate. Monitor Educate Ann Oncol 32:579-581. https://doi.org/10.1016/J.ANNONC.2021.01. 068

11. Joshi A, Kaur M, Kaur R, Grover A, Nash D, El-Mohandes A (2021) Predictors of COVID-19 vaccine acceptance, intention, and hesitancy: a scoping review. Front Public Heal 0:1152. https:// doi.org/10.3389/FPUBH.2021.698111

12. Neumann-Böhme S, Varghese NE, Sabat I, Barros PP, Brouwer W, Exel J van, Schreyögg J, Stargardt T (2020) Once we have it, will we use it? A European survey on willingness to be vaccinated against COVID-19. Eur J Health Econ 21:977-982 . https://doi. org/10.1007/S10198-020-01208-6

13. Barrière J, Gal J, Hoch B, Cassuto O, Leysalle A, Chamorey E, Borchiellini D (2021) Acceptance of SARS-CoV-2 vaccination among French patients with cancer: a cross-sectional survey. Ann Oncol 32:673-674. https://doi.org/10.1016/J.ANNONC.2021.01. 066

14. Villarreal-Garza C, Vaca-Cartagena BF, Becerril-Gaitan A, Ferrigno AS, Mesa-Chavez F, Platas A, Platas A (2021) Attitudes and factors associated with COVID-19 vaccine hesitancy among patients with breast cancer. JAMA Oncol 7:1242-1244. https:// doi.org/10.1001/JAMAONCOL.2021.1962

15. Chan W-L, Ho Y-HT, Wong CK-H, Choi HC-W, Lam K-O, Yuen K-K, Kwong D, Hung I (2021) Acceptance of COVID-19 vaccination in cancer patients in Hong Kong: approaches to improve the vaccination rate. Vaccines 9:792. https://doi.org/10.3390/VACCI NES9070792

16. Cascini F, Pantovic A, Al-Ajlouni Y, Failla G, Ricciardi W (2021) Attitudes, acceptance and hesitancy among the general population worldwide to receive the COVID-19 vaccines and their contributing factors: a systematic review. EClinicalMedicine 40:101113. https://doi.org/10.1016/J.ECLINM.2021.101113

17. Alqudeimat $\mathrm{Y}$, Alenezi $\mathrm{D}$, AlHajri B, Alfouzan $\mathrm{H}$, Almokhaizeem Z, Altamimi S, Almansouri W, Alzalzalah S, Ziyab AH (2021) Acceptance of a COVID-19 vaccine and its related determinants among the general adult population in Kuwait. Med Princ Pract 30:262-271. https://doi.org/10.1159/000514636

Publisher's note Springer Nature remains neutral with regard to jurisdictional claims in published maps and institutional affiliations. 